\title{
Can conservation cut poverty?
}

\section{Experts differ on the effects of biodiversity projects on improvements in living standards.}

World leaders will gather at the United Nations in New York next week to discuss progress on two goals said to be complementary: saving species and lifting people out of poverty. Conservationists often claim that efforts to preserve biodiversity can also benefit the people who rely on natural resources for food and income, and since 2002, the UN Convention on Biological Diversity has linked its conservation plans to poverty alleviation.

Yet despite many small-scale, often anecdotal studies, the evidence for a link is inconclusive. Many studies have simply shown that poverty frequently overlaps with areas that are a high priority for biodiversity conservation.

Disappointing progress on two of the UN's Millennium Development Goals - stemming the loss of biodiversity by 2010 , and lifting half of the world's poorest people out of poverty by 2015 - has focused high-level political interest on potential synergies between the two. So researchers are now tackling wider studies. These projects are finding that although conservationists' optimism is sometimes borne out, synergy can't be taken for granted.

Last year, Will Turner, a researcher at

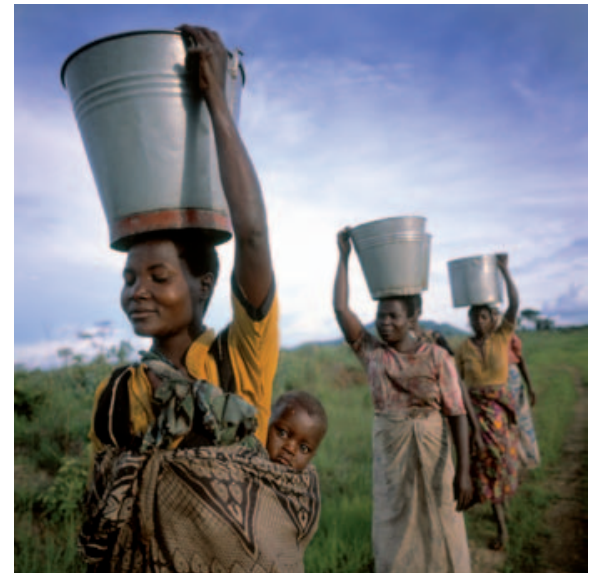

Preserving water supplies can alleviate poverty.

Conservation International, a non-profit agency headquartered in Arlington, Virginia, and his colleagues completed a global assessment of the question, drawing on maps illustrating the extent and function of 17 different ecosystem services, such as water supplies from rivers and streams. The team used the maps to pin down who benefits from the services, and whether conserving these resources was likely to have a marked effect on poverty.

One set of maps drawn up by the international conservation group WWF, headquartered in Gland, Switzerland, used data collected during NASA's Shuttle Radar Topography Mission in 2000 to depict global water networks. Onto these, Turner and his colleagues overlaid LandScan data from the US Department of Energy's Oak Ridge National Laboratory in Tennessee, which uses satellite monitoring of indicators such as roads and land cover to estimate population. Using child malnutrition as a proxy, they estimated the poverty levels of the populations living along rivers shown on the maps.

The researchers then calculated how many people depended on the rivers for their water, whether they had access to other water sources, and how poor they were. They used this to assess whether conservation projects to protect these rivers could also improve people's livelihoods - for example, whether paying for upstream conservation would have knock-on benefits for everyone living along the river.

The study, as yet unpublished, showed that

\section{Tiny traits cause big headaches}

Nanotechnology has invaded the world of biomedicine over the past decade, with scientists increasingly using nanoparticles as potential vehicles for delivering drugs to specific tissues.

Yet the particles are often so poorly understood that their chances of making it off the laboratory bench and into the clinic are being damaged, experts warned at the first international workshop on nanotech medicines held by the European Medicines Agency (EMA) in London earlier this month. They say there is too little rigorous measurement of the particles' basic properties, such as size, shape and surface area. "Characterization is the biggest challenge to this field," Simon Holland, director of process understanding and control at pharmaceutical company GlaxoSmithKline (GSK), headquartered in London, told the conference.

Nanomedicine draws on both biology and materials science, but communication between the two fields has not always been good enough. "In the earlier days, the communities that characterized and the communities that did the cell biology were very different," says Kenneth Dawson, a chemist at University College Dublin and director of Ireland's Centre for BioNano Interactions. The situation is slowly improving, he adds - at least for 'pristine' nanoparticles in the laboratory.

But in the messy biological system of the bloodstream or the cell, the precise form of the nanoparticles is often something of a black box. "Everybody accepts that as an academic community we haven't been characterizing enough," says Dawson. "In the absence of that you'll never get a drug approval licence."

The EMA, which serves a regulatory function similar to that of the US Food and Drug Administration, has approved 18 nanomedicine products so far, most of which are very simple, says Dawson. For example, medicinal liposomes tiny droplets of a drug encased in lipids - are temporary assemblages that are designed to break apart in the body. But smarter nanomedicines with more complex properties are in the pipeline. Liposomes might be coated with polyethylene glycol (PEG) molecules to prevent them from coagulating, for example. The

\section{A SMALL REVOLUTION}

The US National Institutes of Health is funding a growing number of nanotechnology projects.

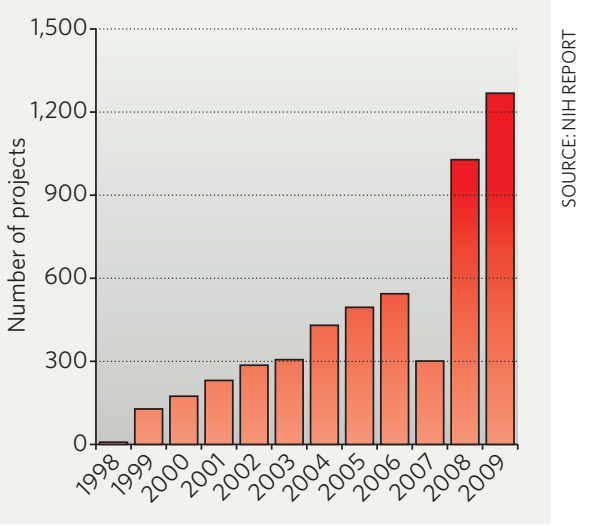


water conservation projects could aid poverty alleviation. The 16 other ecosystem services they assessed, including crop pollination by insects and waste treatment, showed similar results. "This suggests we should continue to push for biodiversity conservation and sustainable development where these synergies exist," says Turner.

But a study published last month by the International Institute for Environment and Development, a non-profit research organization based in London, offered less certainty. Linking Conservation and Poverty Alleviation: the Case of Great Apes (go.nature.com/g6ZpP5) reviewed existing projects to protect apes in Africa, and used follow-up interviews and other "Saying it can't be done is like saying we can't achieve peace."

Amazon should help unpick some of the confusion. The seven-year Ecosystem Services for Poverty Alleviation programme, announced at the end of last year, is being funded with more than $£ 40$ million (US\$62 million) from the UK government's Department for International Development, the Natural Environment Research Council and the Economic and Social Research Council. The first call for projects will come in the next few weeks.

Bill Adams, who studies conservation and poverty at the University of Cambridge, says that conservation and poverty alleviation are not natural bedfellows, not least because development usually goes hand in hand with greater consumption of natural resources. "They are methods to assess whether these are helping to reduce the poverty of local communities.

"We can say that under some circumstances tourism generates lots of money," says co-author Chris Sandbrook, a conservation scientist at the University of Cambridge, UK. But the study was unable to clarify whether the money reaches the poorest people and genuinely leads to a reduction in poverty levels. One problem was the lack of good-quality socio-economic data about the conservation projects, he adds.

A UK-funded programme to catalogue and assess conservation and poverty reduction projects in Africa, South Asia, China and the not in principle incompatible, but most ways of doing poverty alleviation are not good for the environment," he says.

Political leaders must be prepared to make tough choices about where to focus efforts to alleviate poverty, even if there are negative impacts on biodiversity, he adds. But that should not stop them from seeking ways to achieve both. "Saying it can't be done is like saying we can't achieve peace," says Adams. "Maybe we can't stop biodiversity loss and lift people out of poverty at the same time, but we have to try to make it work."

Natasha Gilbert liposomes' ability to deliver a drug will then depend on how many PEG chains there are per particle, and what proportion of those chains are linked to each other. Without characterization of these details, explains Dawson, there would be no way to determine whether a nanomedicine fails a clinical trial because the drug itself is ineffective, or because its carrier is coagulating too much.

Sizing up nanoparticles, even in their pristine state, can prove a problem. Holland noted that in a recent GSK project, the size of drug particles was measured by laser diffraction. But whereas one method of analysing the data gave a median particle size of 740 nanometres, an alternative approach indicated 130 nanometres. Such a large difference could drastically alter drug activity, and there would be no way of pursuing a drug approval application until it was resolved, says Dawson.

As funding pours into the field (see 'A small revolution') attempts are under way in both Europe and the United States to characterize nanoparticles in biological systems. One such problem is that nanoparticles aggregate proteins at their surfaces to form 'protein coronas', which can drastically affect their behaviour. Jim Riviere, director of the Center for Chemical Toxicology Research and Pharmacokinetics at North Carolina State University in Raleigh, and his colleagues recently proposed a biological surface adsorption index that would characterize the corona on the basis of a range of factors, including the distribution of electrons in the nanoparticles, proteins and solvent (X.-R. Xia, N. A. Monteiro-Riviere and J. E. Riviere Nature Nanotechnol. 5, 671-675; 2010). "I personally think we really can't understand a lot about the biological fate of these materials until we develop and validate metrics that actually correlate to biological fate," says Riviere.

Riviere's approach just tackles one of many issues, however. "This is a fiercely debated topic these days," says Justin Teeguarden, a senior scientist at Pacific Northwest National Laboratory in Richland, Washington. "Asking for a gold standard for the community right now is like asking microbiologists what the gold standard for characterizing bacteria should be a few years after microscopes became available."

Daniel Cressey 